\title{
Influence of reproduction traits and pre-weaning growth rate on herd efficiency of different beef breed types in an arid sub-tropical environment
}

\author{
I. du Plessis ${ }^{1,2 \#}$, L.C. Hoffman ${ }^{2}$ and F.J. Calitz ${ }^{2,3}$ \\ ${ }^{1}$ Limpopo Province Department of Agriculture, Mara Research Station, Private Bag X2467, Makhado (Louis Trichardt) \\ 0920, South Africa \\ ${ }^{2}$ Department of Animal Sciences, University of Stellenbosch, Private Bag X1, Matieland 7602, South Africa \\ ${ }^{3}$ ARC Biometry Unit, Private Bag X5013, Stellenbosch 7599, South Africa
}

\begin{abstract}
The efficiency of Simmentaler cross (SX), Bonsmara cross (BX), Afrikaner (AF) and Nguni (NG) cowherds to produce weaner calves under natural sweetveld conditions was investigated. The respective cowherds were selected to differ with regard to frame size (SX $>\mathrm{BX}>\mathrm{AF}>\mathrm{NG}$ ). The AF cows, young (13 to 15 months old) heifers and herd had significantly lower pregnancy rates than the SX, BX and NG cows, young heifers and herds. The weaning rate for NG was significantly higher (15\%) than SX, and although not significant, it was still 5 and $8 \%$ respectively higher than BX and AF. Weaning weight and pre-weaning growth parameters differed significantly between breed types ( $\mathrm{SX}>\mathrm{BX}>\mathrm{AF}>\mathrm{NG}$ ). Cow efficiency was significantly lower for the AF cows than for the SX, BX and NG cows. The NG herd was more efficient than the other three herds, while the AF herd was the least efficient. Differences in herd efficiency were mainly due to differences in the reproduction rates of the respective herds. The reproduction and calf survival rates were the most important production traits that affected herd efficiency. Management practices should be adapted to maximize the reproduction rate of the females, including the young heifers, to maximise herd efficiency.
\end{abstract}

Keywords: Beef cattle, calving rate, survival rate, herd efficiency, pre-weaning growth rate

${ }^{\#}$ Corresponding author. E-mail: iduplessis@lantic.net

\section{Introduction}

In the past, beef cattle in South Africa were used to fulfil multiple functions and the provision of beef was only a secondary or even tertiary function (Van Marle, 1974). However, the application of cattle has changed to such an extent over time that the primary role of beef cattle in modern farming is to produce beef. In the recent past (early 1970's) the introduction of feedlots and export markets has changed the beef production scene dramatically. The increasing demand currently for organically produced food from free ranging animals is adding yet another dimension to beef production. This does not only have an impact on the finishing off of cattle, but will in future inevitably filter through to the whole production chain to include also the primary production unit, the cow and calf herd.

Although it has long been acknowledged that natural grazing plays an important role in extensive beef production (Meaker, 1984), very little information is available on especially production efficiency norms for cowherds under these conditions.

Studies conducted on natural pastures have concentrated mainly on aspects that influence herd efficiency, including calving rate (Steenkamp et al., 1975; Lademann \& Schoeman, 1994); pre-weaning growth (Venter, 1977); supplementation for cows and calves (Lishman et al., 1984; Lademann, 1992; De Waal et al., 1996) as well as crossbreeding (Mentz, 1977; Meaker, 1993). Important production traits and aspects were addressed by these studies and the effect of the various traits and aspects on cow production and efficiency were sometimes illustrated. However, very few studies mentioned the influence of these traits and aspects on the production efficiency of the cowherd.

The effect of mortality rate on herd efficiency was computer-simulated and reported by Du Toit et al. (1995). They concluded that characterisation of breeds, and especially the cowherds in South Africa, needs serious attention. Subsequently, Schoeman (1996) used data from the National Beef Cattle Performance and Progeny Testing Scheme to characterise different cattle breeds in terms of birth weight, pre-weaning performance, post-weaning performance and cow productive efficiency. This characterisation was done 
across various production environments and thus to a large degree reflects only the breed effects. Contrary to these theoretical references to herd efficiency, Tawonezvi et al. (1988) and Schoeman (1989) linked some production traits to herd efficiency in a practical beef production situation.

The aim of this study was to evaluate the efficiency of cowherds from different breed types to produce weaner calves under extensive sweetveld grazing and management conditions.

\section{Materials and Methods}

The study was conducted from 1995 to 2003 on ca. 4387 ha of land on the eastern side of the Mara

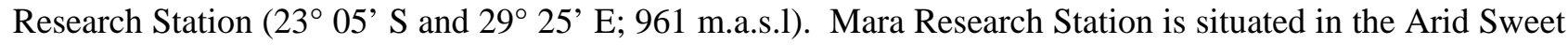
Bushveld of South Africa (Acocks, 1988). The vegetation in the study area includes woody species such as Acacia tortilis, Commiphora pyracanthoides, Boscia albitrunca and Grewia spp. and grass species, Eragrostis rigidior, Panicum maximum, Urochloa mosambicensis and Digitaria eriantha (Dekker et al., 2001). Long-term mean rainfall is $452 \mathrm{~mm}$, of which ca. 80\% occurs from November to March. During the study period, the mean annual rainfall (measured from July to June) was $480 \mathrm{~mm}$, ranging from $232 \mathrm{~mm}$ to $846 \mathrm{~mm}$ (Table 1). Mean daily maximum temperature ranged from $22.6{ }^{\circ} \mathrm{C}$ in June to $30.4{ }^{\circ} \mathrm{C}$ in January.

Simmentaler cross (SX), Bonsmara cross (BX), Afrikaner (AF) and Nguni (NG) cows represented large-framed, large- to medium-framed, small- to medium- and small-framed beef cattle breed types, respectively. As the difference in the actual live weight between the SX and BX cows as well as the AF and NG cows was very similar (Table 2), it was decided to impose weight criteria (Table 2) during the selection of the cows in an effort to ensure that the respective herds differ in frame size.

Table 1 Annual rainfall during the study period (July to June)

\begin{tabular}{cc}
\hline Year & Rainfall $(\mathrm{mm})$ \\
\hline $1995 / 1996$ & 447 \\
$1996 / 1997$ & 533 \\
$1997 / 1998$ & 589 \\
$1998 / 1999$ & 232 \\
$1999 / 2000$ & 343 \\
$2000 / 2001$ & 846 \\
$2001 / 2002$ & 368 \\
Mean & 480 \\
\hline
\end{tabular}

Table 2 Mature weight criteria and cow numbers used to select cows and to balance stocking rates as well as actual mean postpartum weight of cows

\begin{tabular}{lcccc}
\hline Breed type & Abbreviation & $\begin{array}{c}\text { Mature weight criteria } \\
(\mathrm{kg})\end{array}$ & $\begin{array}{c}\text { Number of cows } \\
\text { Postpartum weight } \\
(\mathrm{kg})\end{array}$ & $\begin{array}{c}\text { Pum } \\
\text { Simmentaler cross }\end{array}$ \\
Bonsmara cross & SX & $>500$ & 30 & $486 \pm 73$ \\
Afrikaner & BX & $450-500$ & 32 & $455 \pm 78$ \\
Nguni & AF & $400-450$ & 34 & $431 \pm 57$ \\
& NG & $<400$ & 38 & $337 \pm 49$ \\
\hline
\end{tabular}

The different herds were kept in separate but adjacent camps. To reduce possible camp effects, camps were not allocated in blocks but were randomly and evenly dispersed over the whole study area. Cowherds were kept in close proximity to each other as far as was practically possible. The metabolic body weight (Meissner et al., 1983) of the cows was used to balance the stocking rates and care was taken not to let the stocking rate exceed $12 \mathrm{ha} / \mathrm{LSU}$. 
Cows were exposed to bulls from the first of January for 63 days each year. Calves were born from the end of October until the middle of December. All calves were weaned simultaneously when the last calf reached 205 days of age. Herd management practices (e.g. dipping, vaccination) were standardised for all breeds. No supplementary feeding or licks were supplied. Established herds were used from the onset of the trial and the same culling and replacement strategies were applied to all herds. Throughout the investigation, pregnancy diagnosis was performed by means of rectal palpitation by the same experienced stockman. Cows that were not pregnant or had aborted, were culled from the herd. Similarly, cows that did not wean a calf were culled. This resulted in herd structures that were similar for all breeds and that the effect of dam age on the performance of the herd was assumed to be similar for all herds.

Live weights were recorded at 28-day intervals after withholding food and water for at least 12 hours. Due to this large age difference of the calves at weaning, weaning weights were corrected to a 205-day weight by interpolation. In calculating cow efficiency, the first postpartum weight was used (Venter, 1977). This gave a standardised weight for all cows without the reproductive status of the cow introducing bias into the calculation. Pregnancy rate (PR), calving rate (CR), weaning rate (WR) and cow (CE) and herd efficiencies (HE) were calculated, using the following equations:

$$
\begin{aligned}
& \text { Pregnancy rate }(\mathrm{PR})=\frac{\text { Number of cows pregnant }}{\text { Number of cows mated }} \times 100 \\
& \text { Calving rate }(\mathrm{CR})=\frac{\text { Number of cows calved }}{\text { Number of cows mated }} \times 100 \\
& \text { Weaning rate }(\mathrm{WR})=\frac{\text { Number of cows weaned }}{\text { Number of calves born }} \times 100 \\
& \text { Cow efficiency }(\mathrm{CE})=\frac{\text { Corrected WW }}{\text { Postpartum CW }} \quad \mathrm{x} 100 \\
& \text { Herd efficiency (HE) }=\frac{\text { PR x WR x WW }}{\text { CW at mating }} \times 100 \\
& \text { Where: } \\
& \mathrm{WW} \text { = weaning weight } \\
& \mathrm{CW}=\text { cow weight }
\end{aligned}
$$

In calculating HE, the mean WW and CW at mating for each year were used.

Data were analysed on a herd basis and not on an individual cow basis, and the different years were used as blocks in the statistical analysis of the data. The reproductive data (cows pregnant, cows calved, heifers pregnant, heifers calves, herd pregnant, herd calved and calves weaned) were subjected to a logit transformation before a weighted analysis of variance (Table 3a) was performed (SAS, 2001). Paired t-tests were performed on the least square means on the logit transformed data to compare breeds. For interpretation purposes the above data were back transformed to percentages. Standard analyses of variance (Table 3b) were performed on calf production data (birth weight, weaning weight, average daily gain, total gain cow efficiency and herd efficiency), with years as blocks. Student's t-LSD was calculated at a 5\% significance level to compare breed type means. Shapiro-Wilk's test was performed on the residuals of all the variables to test for deviations from normality.

\section{Results}

There was no evidence against normality for all the variables. Therefore, the results can be considered as representative of the populations. The evidence for significant differences between years occurred only for weaning weight and average daily gain (Table 3a, b). However, the assumption was made that this effect would be equally applicable to all the breeds. 
Table 3a Weighted analyses of variance on the logit transformed data for cows pregnant, cows calved, heifers pregnant, heifers calves, herd pregnant, herd calved and calves weaned

\begin{tabular}{|c|c|c|c|c|c|c|c|c|c|c|c|c|}
\hline \multirow{2}{*}{ Effects } & \multicolumn{3}{|c|}{ Cows pregnant } & \multicolumn{3}{|c|}{ Cows calved } & \multicolumn{3}{|c|}{ Heifers pregnant } & \multicolumn{3}{|c|}{ Heifers calved } \\
\hline & DF & MS & $\mathrm{P}$ & DF & MS & $\mathrm{P}$ & DF & MS & $\mathrm{P}$ & DF & MS & $\mathrm{P}$ \\
\hline Yea & 6 & 2.287 & 0. & 6 & 3.233 & 0.0 & 6 & 1.575 & 0.09 & 6 & 0.955 & 0.18 \\
\hline Breed & 3 & 6.676 & $<0.01$ & 3 & 6.834 & $<0.01$ & 3 & 8.633 & $<0.01$ & 3 & 8.513 & $<0.01$ \\
\hline Error & 15 & 1.110 & & 15 & 1.232 & & 15 & 0.675 & & 15 & 0.549 & \\
\hline Total Corrected & 24 & & & 24 & & & 24 & & & 24 & & \\
\hline
\end{tabular}

\begin{tabular}{lccccccccc}
\multirow{2}{*}{ Effects } & \multicolumn{3}{c}{ Herd pregnant } & \multicolumn{3}{c}{ Herd calved } & \multicolumn{3}{c}{ Calves weaned } \\
\cline { 2 - 10 } & DF & MS & P & DF & MS & P & DF & MS & P \\
\hline Year & 6 & 2.287 & 0.12 & 6 & 3.233 & 0.06 & 6 & 3.233 & 0.06 \\
Breed & 3 & 6.676 & $<0.01$ & 3 & 6.834 & $<0.01$ & 3 & 6.834 & $<0.01$ \\
Error & 15 & 1.110 & & 15 & 1.232 & & 15 & 1.232 & \\
Total Corrected & 24 & & & 24 & & & 24 & &
\end{tabular}

DF - Degrees of freedom; MS - Means squared; P - Significance level

Table $3 \mathbf{b}$ Analyses of variance on birth weight, weaning weight, average daily gain, total gain cow efficiency and herd efficiency

\begin{tabular}{|c|c|c|c|c|c|c|c|c|c|}
\hline \multirow{2}{*}{ Effects } & \multicolumn{3}{|c|}{ Birth weight } & \multicolumn{3}{|c|}{ Weaning weight } & \multicolumn{3}{|c|}{ Average daily gain } \\
\hline & DF & MS & $\mathrm{P}$ & DF & MS & $\mathrm{P}$ & DF & MS & $\mathrm{P}$ \\
\hline Year & 6 & 5.597 & 0.09 & 6 & 438.7 & 0.02 & 6 & 11258. & $<0.01$ \\
\hline Breed & 3 & 240.16 & $<0.01$ & 3 & 7315.2 & $<0.01$ & 3 & 115516. & $<0.01$ \\
\hline Error & 15 & 2.439 & & 14 & 109.2 & & 15 & 2489. & \\
\hline Total Corrected & 24 & & & 23 & & & 24 & & \\
\hline \multirow{2}{*}{ Effects } & \multicolumn{3}{|c|}{ Total gain cow } & \multicolumn{3}{|c|}{ Cow efficiency } & \multicolumn{3}{|c|}{ Herd efficiency } \\
\hline & DF & MS & $\mathrm{P}$ & DF & MS & $\mathrm{P}$ & $\mathrm{DF}$ & MS & $\mathrm{P}$ \\
\hline Year & 6 & 490.7 & $<0.01$ & 6 & 8.910 & $<0.01$ & 6 & 57.52 & 0.01 \\
\hline Breed & 3 & 5078.1 & $<0.01$ & 3 & 48.027 & $<0.01$ & 3 & 246.45 & $<0.01$ \\
\hline Error & 14 & 99.4 & & 14 & 8.344 & & 15 & 13.56 & \\
\hline Total Corrected & 23 & & & 23 & & & 24 & & \\
\hline
\end{tabular}

DF - Degrees of freedom; MS - Means squared; P - Significance level

The cows of the NG breed had a $10-20 \%$ higher pregnancy rate $(\mathrm{P}<0.05)$ than the cows of the other breeds (Table 4). The same breed effect was observed for the percentage cows calved. However, as pertaining to the heifers, the AF breed performed significantly poorer than the other breeds, which did not differ from each other. The results of the cow and heifer pregnancy rates resulted in the NG herd having the highest pregnancy and calving rates $(\mathrm{P}<0.05)$ and the AF the lowest $(\mathrm{P}<0.05)$. The difference between the number of cows pregnant and number of cows calved could be attributed to either erroneous pregnancy diagnosis or to abortions.

No data were available for NG and SX cows for 1995, since the NG cows and some SX cows were transferred to the Mara Research Station during 1995. This means that no initial data were available for the NG herd. The SX herd, in addition, had a low PR due to adaptation problems. The AF cattle were relocated from the Mara Research Station at the end of 2000 and further data (after 2000) were therefore not available for this breed. 
The NG breed had a 15\% $(\mathrm{P}<0.05)$ higher weaning rate than the SX (Table 5). Both these breeds did not differ in their respective weaning rates from the $\mathrm{BX}$ and $\mathrm{AF}$ breeds $(\mathrm{P}>0.05)$.

Table 4 Least square means ( \pm s.e.) of weighted logit transformed data for or cows, heifers and herd pregnant and calved per breed. Back transformed percentages in parenthesis

\begin{tabular}{|c|c|c|c|c|c|c|}
\hline \multirow{2}{*}{ Breed type } & \multicolumn{3}{|c|}{ Cows } & \multicolumn{3}{|c|}{ Heifers } \\
\hline & Mated & Pregnant & Calved & Mated & Pregnant & Calved \\
\hline Simmentaler & 141 & $1.16^{\mathrm{b}}$ & $0.95^{b}$ & 44 & $0.27^{\mathrm{a}}$ & $-0.07^{\mathrm{a}}$ \\
\hline cross & & $\pm 0.241(76)$ & $\pm 0.246(72)$ & & $\pm 0.266(57)$ & $\pm 0.235(48)$ \\
\hline Bonsmara cross & 188 & $\begin{array}{c}1.52^{\mathrm{b}} \\
\pm 0.207(82)\end{array}$ & $\begin{array}{c}1.45^{\mathrm{b}} \\
\pm 0.213(81)\end{array}$ & 66 & $\begin{array}{c}0.08^{\mathrm{a}} \\
\pm 0.207(52)\end{array}$ & $\begin{array}{c}-0.10^{\mathrm{a}} \\
\pm 0.187(48)\end{array}$ \\
\hline Afrikaner & 163 & $\begin{array}{c}0.94^{\mathrm{b}} \\
\pm 0.210(72)\end{array}$ & $\begin{array}{l}0.86^{b} \\
\pm 0.220(70)\end{array}$ & 54 & $\begin{array}{l}-2.17^{\mathrm{b}} \\
\pm 0.369(10)\end{array}$ & $\begin{aligned} & -2.64^{\mathrm{b}} \\
\pm & 0.392(7)\end{aligned}$ \\
\hline Nguni & 180 & $\begin{array}{c}2.48^{\mathrm{a}} \\
\pm 0.313(92)\end{array}$ & $\begin{array}{c}2.32^{\mathrm{a}} \\
\pm 0.321(91)\end{array}$ & 64 & $\begin{array}{c}0.52^{\mathrm{a}} \\
\pm 0.229(63)\end{array}$ & $\begin{array}{c}0.38^{\mathrm{a}} \\
\pm 0.206(59)\end{array}$ \\
\hline
\end{tabular}

\begin{tabular}{lccc} 
Breed type & \multicolumn{3}{c}{ Herd } \\
\cline { 2 - 4 } & Mated & Pregnant & Calved \\
\hline Simmentaler & 185 & $1.03^{\mathrm{b}}$ & $0.79^{\mathrm{b}}$ \\
cross & & $\pm 0.186(74)$ & $\pm 0.193(69)$ \\
Bonsmara cross & 254 & $1.06^{\mathrm{b}}$ & $0.94^{\mathrm{b}}$ \\
& & $\pm 0.156(74)$ & $\pm 0.163(72)$ \\
Afrikaner & 217 & $0.27^{\mathrm{c}}$ & $0.21^{\mathrm{c}}$ \\
& & $\pm 0.150(57)$ & $\pm 0.162(55)$ \\
Nguni & 244 & $1.76^{\mathrm{a}}$ & $1.61^{\mathrm{a}}$ \\
& & $\pm 0.196(85)$ & $\pm 0.204(85)$
\end{tabular}

${ }^{a, b}$ Column means with different superscripts differ $(\mathrm{P}<0.05)$

Table 5 Least square means ( \pm s.e.) of weighted Logit transformed data for calves weaned per breed. Back transformed percentages in parenthesis

\begin{tabular}{lcr}
\hline Breed type & Number of calves born & Calves weaned \\
\hline Simmentaler cross & 133 & $1.09^{\mathrm{b}} \pm 0.263(75)$ \\
Bonsmara cross & 187 & $1.75^{\mathrm{ab}} \pm 0.262(85)$ \\
Afrikaner & 118 & $1.53^{\mathrm{ab}} \pm 0.377(82)$ \\
Nguni & 209 & $2.19^{\mathrm{a}} \pm 0.311(90)$ \\
\hline
\end{tabular}

${ }^{\mathrm{a}}$ Column means with different superscripts differ $(\mathrm{P}<0.05)$

Breed had a significant effect on the birth weight, adjusted weaning weights and total gain of the calves (Table 6). These weights were directly linked to the frame sizes of the dams, with the larger animals having the heavier calves. The calves from the larger framed SX cows gained more than $100 \mathrm{~g} /$ day than the $\mathrm{BX}(\mathrm{P}<0.05)$. The latter gained more than $150 \mathrm{~g} /$ day than the AF. Although the average daily gain of the $\mathrm{AF}$ and NG did not differ ( $\mathrm{P}>0.05$ ), the significantly higher birth weight of the former resulted in the AF having a heavier $(\mathrm{P}<0.05)$ adjusted weaning weight. 
The AF cows had a lower CE and HE $(\mathrm{P}<0.05)$ than the SX, BX and NG cows (Table 7). Although there was no significant difference in CE between the SX, BX and NG, the NG breed had a higher HE $(\mathrm{P}<0.05)$.

Table 6 Least square means ( \pm s.e.) for birth weight, weaning weight, average daily gain, total pre-weaning gain and cow efficiency by breed type

\begin{tabular}{lcccc}
\hline Breed type & $\begin{array}{c}\text { Birth weight } \\
(\mathrm{kg})\end{array}$ & $\begin{array}{c}\text { Weaning weight } \\
(\mathrm{kg})\end{array}$ & $\begin{array}{c}\text { Average daily gain } \\
(\mathrm{g} / \text { day })\end{array}$ & $\begin{array}{c}\text { Total gain } \\
(\mathrm{kg})\end{array}$ \\
\hline Simmentaler cross & $41.3^{\mathrm{a}} \pm 0.66$ & $241^{\mathrm{a}} \pm 4.4$ & & \\
Bonsmara cross & $36.1^{\mathrm{b}} \pm 0.59$ & $213^{\mathrm{b}} \pm 4.0$ & $868^{\mathrm{a}} \pm 21.1$ & $201^{\mathrm{a}} \pm 4.2$ \\
Afrikaner & $31.7^{\mathrm{c}} \pm 0.65$ & $178^{\mathrm{c}} \pm 4.9$ & $714^{\mathrm{b}} \pm 18.9$ & $176^{\mathrm{b}} \pm 3.8$ \\
Nguni & $26.5^{\mathrm{d}} \pm 0.66$ & $162^{\mathrm{d}} \pm 4.4$ & $659^{\mathrm{c}} \pm 23.4$ & $149^{\mathrm{c}} \pm 4.7$ \\
& & & & $136^{\mathrm{d}} \pm 4.2$
\end{tabular}

${ }_{\mathrm{a}, \mathrm{b}, \mathrm{c}, \mathrm{d}}$ Column means with different superscripts differ $(\mathrm{P}<0.05)$

Table 7 Least square means ( \pm s.e.) for cow and herd efficiencies by breed

\begin{tabular}{lcc}
\hline Breed type & $\begin{array}{c}\text { Cow efficiency } \\
(\%)\end{array}$ & $\begin{array}{c}\text { Herd efficiency } \\
(\mathrm{kg} / 100 \mathrm{~kg} \text { mated })\end{array}$ \\
\hline Simmentaler cross & $48.7^{\mathrm{a}} \pm 1.22$ & $27.6^{\mathrm{b}} \pm 1.55$ \\
Bonsmara cross & $46.9^{\mathrm{a}} \pm 1.09$ & $31.0^{\mathrm{b}} \pm 1.39$ \\
Afrikaner & $41.5^{\mathrm{b}} \pm 1.36$ & $20.9^{\mathrm{c}} \pm 1.73$ \\
Nguni & $47.9^{\mathrm{a}} \pm 1.22$ & $37.6^{\mathrm{a}} \pm 1.56$ \\
\hline
\end{tabular}

\footnotetext{
a,b,c,d Column means with different superscripts differ $(\mathrm{P}<0.05)$
}

\section{Discussion}

Due to the limited space that was available for this study as well as the extensive nature of the study, the different herds comprised only a small number of animals (Table 2). One cow therefore represented approximately $3 \%$ of the herd and one calf approximately $4 \%$ of the calf crop. Calculating PR and WR on a yearly basis for each herd resulted in the lower than expected PR and WR. The calculated HE was thus also probably lower than would be expected.

Marincowitz (1978), Van Niekerk et al. (1985), De Brouwer et al. (1993), Lademann \& Schoeman (1994) and Collins-Lusweti (2000) reported reproduction results similar to that of the current study. Based on these results it is accepted that under extensive arid sweetveld conditions smaller framed animals have higher reproductive rates than larger framed animals. However, contradictory results concerning the reproduction rates of cattle from different frame sizes also exist. In this regard Steenkamp \& Van der Horst (1974) reported that large- and medium-framed AF cows grazing natural pastures had significantly (P < 0.01) higher calving rates than small-framed AF cows. However, the results of Vargas et al. (1999) supported the more popular view that small-framed cows have higher calving rates $(\mathrm{P}<0.01)$ than mediumor large-framed Brahman cows on cultivated pastures and nutritional supplementation in winter. The results from the present study suggest that the inherent reproductive traits of the breed may play a more pronounced role in the expression of the reproduction rate than frame size. The age at which reproductive maturity is reached may contribute appreciably to the differences observed in the reproduction rates of the different breed types.

Van der Merwe \& Schoeman (1995) reported calving rates for Simmentaler heifers mated at 14 months of age (60.8\%) that are similar to the PR observed for the SX in the present study. However, Scholtz et al. (1991) reported a lower PR for early mated NG heifers (37\%), while Lepen et al. (1993) reported higher PR values of $79.3 \%$ and $80.0 \%$ for pasture and intensively reared, early mated NG heifers, 
respectively. Simmentaler heifers mated at 24 months of age had a higher calving rate $(\mathrm{P}<0.01)$ than heifers mated at 14 months of age (Van der Merwe \& Schoeman, 1995). Similar results were reported for AF x Sussex heifers (Meaker et al., 1980) and NG heifers (Scholtz et al., 1991).

Pregnancy rate at 13 to 15 months of age was low and variable and probably related to whether environmental conditions were conducive to the early onset of puberty or not. The extremely low PR of the AF heifers suggests that AF heifers reached puberty at a later age than the other breeds.

Age at puberty (first oestrus) varied according to breed (Lepen et al., 1993), frame size (Vargas et al., 1999), management (Van der Merwe \& Schoeman, 1995) and nutrition (Klosterman, 1981; Lepen et al., 1993). According to Lepen et al. (1993) the age at which puberty was reached varied from 344 days ( 11 months) to 418 days ( 13.5 months) and, according to Vargas et al. (1999), from 633 ( 21 months) to 672 days $(\sim 22$ months). Although there is a large difference between these reports, both indicate that puberty was reached during or after the mating season if the heifers were mated at 13 to 15 months of age. However, in most cases puberty was reached before mating at two years of age. These results provided reasons for the low and variable PR for young heifers. Nutritional fluctuations between years will also increase the variation in the PR of the young heifers. Although Klosterman (1981) indicated that by combining reproduction with growth of immature heifers assisted in reducing the feed costs of cattle production systems, results from the present study suggested that if heifers are to be mated at this young age, adequate supplementary feeding should be allowed for to maintain acceptable reproductive levels.

The low PR observed for AF herd is most probably an inherent characteristic of the breed, as various reports also indicated low reproduction rates in AF cattle under extensive production environments, e.g. at the Omatjene Research Station in Namibia (Schoeman, 1989), Potchefstroom in the Northwest Province of South Africa (De Brouwer et al., 1993) and in Zimbabwe (Tawonezvi et al., 1988).

The differences in pre-weaning growth rate parameters were expected, as various reports indicated that larger-framed breed types tend to gain weight at faster rates than smaller-framed breed types. Van Zyl (1990) and Meaker (1993) reported differences $(\mathrm{P}<0.05)$ in weaning weight between Simmentaler, Bonsmara and AF calves. The results obtained by Dadi et al. (2002a) that larger-framed Charolais-sired calves were heavier $(\mathrm{P}<0.001)$ at birth (38.4 vs. 33.4) and weaning (197.1 vs. 177.5) than the smaller-framed Hereford-sired calves, supported the results observed in the present study. These authors also indicated that Bonsmara cows gave birth to and weaned heavier calves $(\mathrm{P}<0.05)$ than Hereford and Angus cows. Medium- and largeframed AF cows weaned heavier calves than small-framed AF cows (Steenkamp \& Van der Horst, 1974). Similar results were reported for Brahman cows differing in frame size (Vargas et al., 1999). Heavier BW and WW for larger-framed breed types compared to smaller-framed breed types have been reported widely (Venter, 1977; Mentz et al., 1979; Tawonezvi et al., 1988; Schoeman, 1989, 1996; Van Zyl et al., 1992; De Brouwer et al., 1993; Collins-Lusweti, 2000). Venter (1977) reported live weight gains from birth to weaning similar to those observed in the present study for Bonsmara and AF calves, but a lower live weight gain of $172.4 \mathrm{~kg}$ for Simmentaler calves, while Hereford calves gained weight at a similar rate to the NG calves. Vargas et al. (1999) explained that these differences for the pre-weaning growth traits are likely to reflect a positive phenotypic correlation between milk production and the body size of the cow; the inherent growth pattern of large-framed calves; and the ability of fast-gaining calves to increase forage intake to meet their increasing nutritional demands.

The results for WR differ from the results of Tawonezvi et al. (1988) and Vargas et al. (1999), who recorded no significant differences in WR between various breed types and various frame sized cows, respectively. However, Schoeman (1989) reported lower pre-weaning losses of 6.17, 6.28 and 3.61\% for Simmentaler, AF and NG cows, respectively. Afrikaner cows under Highland Sourveld conditions weaned fewer calves than Simmentaler cows (62.6\% vs. 76.6\%), but the WR was noted to be similar (91.1\% vs. 93.4\%) for the two breeds under Lowveld Thornveld conditions (Van Niekerk et al., 1985).

The faster growth rates achieved by the SX and BX calves resulted in heavier weaning weights for the SX and BX than the AF and NG calves. Thus, the CE-values of the different breed types were very similar. Although the AF cows were significantly $(\mathrm{P}<0.05)$ less efficient than the other breeds, the differences in $\mathrm{CE}$ were relatively small.

Schoeman (1989) also found that AF cows had a lower CE than Simmentaler and Sanga cows. Tawonezvi et al. (1988) recorded similar results for several cow productivity parameters for various AF crossbred cows. Lepen et al. (1993) reported similar CE-values to those observed in the present study for NG 
heifers mated at either 13 months (47.1) or 15 months of age (43.5). Meaker (1993), on the contrary, reported that CE indices (expressed as WW to $\mathrm{CW}^{0.75}$ ) for purebred Simmentaler cows were higher $(\mathrm{P}<0.05)$ than for Bonsmara and AF cows at the Mara Research Station. These results emphasise that CE is more important as a selection criterion than as a measure of production efficiency of the herd. This statement is supported by the comment of Vargas et al. (1999) that the weight of calf weaned per cow mated is more important than weaning weight per se.

Herd efficiency, as expressed by the equation used in this study, is a function of calving rate, calf survival rate and calf weaning weight. Although slightly different equations were used, the results from the present study as well as the studies of Schoeman (1989) and Tawonezvi et al. (1988) are very similar.

Breed and frame size influenced HE in a similar fashion as the reproduction rate of the cows, since herd efficiency is closely linked to reproduction rate. From HE values observed in this study, it is evident that the reproductive and calving rates were the most important factors for determining HE, since the NG herd was the most effective, notwithstanding the fact that NG calves grew at the slowest rates. A $10 \%$ change in calving rate, calf survival or growth rate resulted in a $4.9 \%, 4.4 \%$ and $3.7 \%$ change in HE, respectively. This observation is in agreement with previous reports that the profitability of the cowherd is greatly dependent on reproduction rate (Lamond, 1970; Venter \& Luitingh, 1980).

\section{Conclusions}

The reproduction rate of the cowherd and the survival rate of the calves are the most important factors determining the efficiency of the cowherd. Simmentaler and Bonsmara type cattle, as well as Nguni cattle, maintained acceptable productivity levels while grazing natural sweetveld pastures without nutritional supplements and hold the possibility to produce weaner calves organically. Inherent characteristics such as maintenance requirements, susceptibility to parasites and diseases of individual breeds should, however, be taken into account. Susceptibility to diseases and parasites in particular, will influence the frequency with which animals have to be treated and therefore also the organic status of the production enterprise. Management practices should be adapted to maximise the reproduction rate, as well as the calf survival rate, and thus the production efficiency of the specific breed without compromising the organic status of the herd. Market preferences should also receive consideration. Large-framed breed types produce calves that grow faster and wean heavier than smaller framed breed types, which may be more acceptable to feedlots. On the other hand, smaller-framed, indigenous Sanga breeds such as the Nguni, with their ability to finish relatively easily under extensive grazing conditions, may be better suited to extensive finishing systems. While further and more decisive research concerning the standardisation and refining of the definition of, as well as the norm for production efficiency on a herd or enterprise basis is undoubtedly necessary, the ability and efficiency of different breed types with regard to finishing from natural pastures and thus supplying the demand for organically produced meat should also be investigated further.

\section{References}

Acocks, J.P.H., 1988. Veld types of South Africa. Memoirs of the Botanical Survey of South Africa 57.

Collins-Lusweti, E., 2000. Performance of Nguni, Afrikander and Bonsmara cattle under drought conditions in the North West Province of Southern Africa. S. Afr. J. Anim. Sci. 30, 33.

Dadi, H., Jordaan, G.F., Schoeman, S.J. \& Van der Westhuizen, J., 2002a. The influence of Charolais and Hereford sires and straightbred and crossbred dams on pre-weaning growth performance of calves. S. Afr. J. Anim. Sci. 32, 38-43.

Dadi, H., Jordaan, G.F., Schoeman, S.J. \& Van der Westhuizen, J., 2002b. The influence of Charolais and Angus breeding levels on pre-weaning growth performance traits in crossbred calves. S. Afr. J. Anim. Sci. 32, 201-207.

De Brouwer, C.H.M., Visser, C.B., Schutte, A.R. \& Postma, M., 1993. Biological and economical effects of different supplements given to beef cows on summer grazing. S. Afr. J. Anim. Sci. 23, 31-37.

Dekker, B., Kirkman, K.P. \& Du Plessis, S.I., 2001. Use of the dry-weight-rank method of botanical analysis in semi-arid savanna communities. Afr. J. Range For. Sci. 19, 63-68.

De Waal, H.O., Randall, J.H. \& Koekemoer, G.J., 1996. The effects of phosphorus supplementation on body mass and reproduction of grazing beef cows supplemented with different levels of phosphorus at Armoedsvlakte. S. Afr. J. Anim. Sci. 26, 29-36. 
Du Toit, P., Van der Westhuizen, J., Scholtz, M.M. \& Mostert, B.E., 1995. Effect of mortality rate and breed on total herd efficiency. S. Afr. J. Anim. Sci. 25, 57-60.

Klosterman, E.W., 1981. Measuring beef production in the cow herd. S. Afr. J. Anim. Sci. 11, 195-198.

Lademann, E.E., 1992. Faktore wat die herkonsepsie van vleisraskoeie in die Noord-Transvaalse Soetbosveld beïnvloed. MSc (Agric) thesis, University of Pretoria, South Africa.

Lademann, E.E. \& Schoeman, S.J., 1994. Factors influencing recalving rate in lactating beef cows in the sweet dry Bushveld of northern Transvaal. S. Afr. J. Anim. Sci. 24, 30-33.

Lamond, D.R., 1970. The influence of undernutrition on reproduction in the cow. Anim. Breed. Abstr. 38, 359.

Lepen, J.M., Schoeman, S.J. \& Venter, H.A.W., 1993. Influence of first calving age and nutrition on the performance of early mated Nguni heifers. S. Afr. J. Anim. Sci. 23, 204-206.

Lishman, A.W., Lyle, A.D., Smith, V.W. \& Botha, W.A., 1984. Conception rate of beef cows and growth of suckling calves as influenced by date of calving and supplementary feeding. S. Afr. J. Anim. Sci. 14, 10-19.

Marincowitz, G., 1978. Vrugbaarheid van vleisbeeste op die Soutpan beesplaas. S. Afr. J. Anim. Sci. 8, 119123.

Meaker, H.J., 1984. Effective extensive beef production as a prelude to feedlotting. S. Afr. J. Anim. Sci. 14, 158-163.

Meaker, H.J., Coetsee, T.P.N. \& Lishman, A.W., 1980. The effects of age at first calving on the productive and reproductive performance of beef cows. S. Afr. J. Anim. Sci. 10, 105-113.

Meaker, M.J., 1993. The effect of genotype on cow efficiency in extensive beef production in the northern Transvaal sweet Bushveld. MSc (Agric) thesis, University of Pretoria, South Africa.

Meissner, H.H., Hofmeyr, H.S., Van Rensburg, W.J.J. \& Pienaar, J.P., 1983. Classification of livestock for realistic prediction of substitution values in terms of a biologically defined Large Stock Unit. Technical Communication No. 175, Department of Agriculture, Republic of South Africa.

Mentz, A.H., 1977. Produksiepotensiaal van verskillende eerstekruising Afrikanerbeeste. MSc (Agric) thesis, University of the Orange Free State, South Africa.

Mentz, A.H., Els, D.L. \& Coetzer, W.A., 1979. Crossbreeding with Africander dam as basis. 2. Weaning performance of progeny of various sire breeds. S. Afr. J. Anim. Sci. 9, 205-208.

SAS, 2001. SAS/STAT Users Guide. The SAS System for Windows, Version 9.13, ed. SAS Institute Inc., Cary, N.C., USA. pp. 1028.

Schoeman, S.J., 1989. Recent research into the production potential of indigenous cattle with special reference to the Sanga. S. Afr. J. Anim. Sci. 19, 206-209.

Schoeman, S.J., 1996. Characterization of beef cattle breeds by virtue of their performance in the National Beef Performance and Progeny Testing Scheme. S. Afr. J. Anim. Sci. 26, 15-19.

Scholtz, M.M., Lombard, P.E. \& Enslin, C.B., 1991. A note on the early mating of beef heifers. S. Afr. J. Anim. Sci. 21, 55-61.

Steenkamp, J.D.G. \& Van der Horst, C., 1974. The relationship between size and efficiency in the beef cow. S. Afr. J. Anim. Sci. 4, 81-91.

Steenkamp, J.D.G., Van der Horst, C. \& Andrew M.J.A., 1975. Reconception in grade and pedigree Africander cows of different sizes - postpartum factors influencing reconception. S. Afr. J. Anim. Sci. 5, 103-110.

Tawonezvi, H.P.R., Ward, H.K., Trail, J.C.M. \& Light, D., 1988. Evaluation of beef breeds for rangeland weaner production in Zimbabwe. Anim. Prod. 47, 361-367.

Van der Merwe, P.S. \& Schoeman, S.J., 1995. Effect of early calving of Simmentaler heifers under an extensive management system. S. Afr. J. Anim. Sci. 25, 36-39.

Van Marle, J., 1974. The breeding of beef cattle in South Africa: Past, present and future. S. Afr. J. Anim. Sci. 4, 297-304.

Van Niekerk, A., Lishman, A.W. \& Lesch, S.F., 1985. The reproductive responses of two breeds of beef cows and the performance of their progeny in two contrasting environments. S. Afr. J. Anim. Sci. 16, 209-214.

Van Zyl, J.G.E., 1990. Studies on the performance and efficiency of pure and crossbred cattle in an arid Bushveld environment. PhD (Agric) thesis, University of Pretoria, South Africa. 
Van Zyl, J.G.E., Schoeman, S.J. \& Coertze, R.J., 1992. Sire breed and genotype of dam effects in crossbreeding beef cattle in the subtropics. 1. Birth and weaning mass of calves. S. Afr. J. Anim. Sci. 22, 161-165.

Vargas, C.A., Olsen, T.A., Chase Jr., C.C., Hammond, A.C. \& Elzo, M.A., 1999. Influence of frame size and body condition score on performance of Brahman cattle. J. Anim. Sci. 77, 3140-3149.

Venter, H.A.W., 1977. Die invloed van voorspeense groei by sekere vleis-, dubbeldoel- en kruisrasse in die Noord-Transvaalse Soetbosveld. DSc (Agric) thesis, University of Pretoria, South Africa.

Venter, H.A.W. \& Luitingh, H.C., 1980. 'n Beesvleisproduksiestrategie vir die Transvaalse Bosveld en Noord-Kaap. S. Afr. J. Anim. Sci. 10, 311-322. 